Research Paper

\title{
Insights into the Hallmarks of Human Nucleus Pulposus Cells with Particular Reference to Cell Viability, Phagocytic Potential and Long Process Formation
}

\author{
Yu-Fei Chen ${ }^{1, \dagger}$, Yong-Zhao Zhang1, $\dagger$, Wei-Lin Zhang1, $\dagger$, Guan-Nan Luan ${ }^{2, \dagger}$, Zhi-Heng Liu1, $\dagger$, Yang Gao ${ }^{1}$, \\ Zhong-Yuan Wan ${ }^{1}$, Zhen Sun ${ }^{1}$, Shu Zhu ${ }^{1}$, Dino Samartzis ${ }^{3}$, Chun-Mei Wang ${ }^{1}$, Hai-Qiang Wang1 ${ }^{\bowtie}$, \\ Zhuo-Jing Luo ${ }^{1 凶}$ \\ 1. Department of Orthopaedics, Xijing Hospital, Fourth Military Medical University, Xi'an, China; \\ 2. National Science Library, Chinese Academy of Sciences, Beijing, People's Republic of China; \\ 3. Department of Orthopaedics and Traumatology, University of Hong Kong, Pokfulam, Hong Kong, SAR China \\ †These authors contribute equally to this work.
}

$\triangle$ Corresponding author: Hai-Qiang Wang, Zhuo-Jing Luo, Department of Orthopaedics, Xijing Hospital, 127 Changle Western Road, Fourth Military Medical University, Xi'an, P. R. China, 710032. E-mail: hqwang@fmmu.edu.cn, zjluo@fmmu.edu.cn FAX: +86 2984775285 Phone: +86 2984775285 .

(c) Ivyspring International Publisher. This is an open-access article distributed under the terms of the Creative Commons License (http://creativecommons.org/ licenses/by-nc-nd/3.0/). Reproduction is permitted for personal, noncommercial use, provided that the article is in whole, unmodified, and properly cited.

Received: 2013.04.22; Accepted: 2013.10.14; Published: 2013.10.31

\begin{abstract}
Objective: As a main cellular component within the disc, nucleus pulposus (NP) cells play important roles in disc physiology. However, little is known on the biologic hallmarks of human NP cells. Therefore, the present study aimed to address the features of human NP cells.

Methods: Human NP samples were collected from normal cadavers, patients with scoliosis and disc degeneration as normal, disease control and degenerative NP, respectively. The NP samples were studied using transmission electron microscopy and TUNEL assay. Pre-digested NP samples were studied using flow cytometry with Pl/Annexin $\mathrm{V}$ staining.

Results: Both control and degenerative human NP consisted of mainly viable cells with a variety of morphology. Both necrosis and apoptosis were noted in human NP as forms of cell death with increased apoptosis in degenerative NP, which was further confirmed by the TUNEL assay. Phagocytic NP cells had the hallmarks of both stationary macrophages with lysosomes and NP cells with the endoplasmic reticulum. Annulus fibrosus cells have similar morphologic characteristics with NP cells in terms of cell nest, phagocytosis and intracellular organs. Moreover, NP cells with long processes existed in degenerative and scoliotic NP rather than normal NP. When cultured in glucose-free medium, NP cells developed long and thin processes.

Conclusion: Human degenerative NP consists of primarily viable cells. We present direct and in vivo evidence that both human annulus fibrosus and NP cells have phagocytic potential. Moreover, NP cells with long processes exist in both scoliotic and degenerative NP with lack of glucose as one of the possible underlying mechanisms.
\end{abstract}

Key words: annulus fibrosus, nucleus pulposus, disc degeneration, apoptosis, flow cytometry, electronic microscopy, TUENL assay, human, cell culture.

\section{INTRODUCTION}

As conjunctive structure to act as buffers between adjacent vertebral bodies, the intervertebral disc is composed of an outer fibrous layer, the annulus fibrosus (AF), and an inner gelatinous core rich in 
proteoglycans, the nucleus pulposus (NP). NP cells are the builder and maintainer of extracellular matrix (ECM) of NP [1]. The adult human NP consists of mainly small chondrocyte-like cells other than the alleged notochondral cells with granular cytoplasmic inclusions [2-4]. Intervertebral disc degeneration (IDD) is characterized histologically by alternations at the cellular level $[5,6]$. It has been noted that increased disc cell proliferation and cell-cluster formation [7], as well as increased cell death [5, 8] during IDD.

Clear progress has been achieved over the past decades, addressing the biologic hallmarks of NP cells as well as in vitro cultures [6, 9-15]. However, the question of the cell death forms and occurrence of NP cells remains open. Due to the avascular structure of the NP, several studies reported that cell death within the NP is common $[2,16]$. However, opposing opinions exist regarding the cell death occurrence issue [17]. Furthermore, despite cell clusters are noted as one of the traits of IDD $[5,7]$, the underlying mechanisms of cell cluster formation have not been elucidated. Therefore, it is of critical importance to clarify the hallmarks of human NP cells and to further clarify the etiology and therapeutic strategies of IDD at cellular level.

To further address these issues, we explored the ultrastructure of human NP cells using transmission electronic microscopy and cell death within the NP using flow cytometry and TUENL assay. Details on human NP cell cultures in monolayer were noted.

\section{MATERIALS AND METHODS}

\section{Ethics Statement}

The institutional ethics review board of Xijing Hospital, Fourth Military Medical University approved the study (No. 20111103-7). Moreover, we obtained written informed consent for the experimental use of the disc from normal cadavers and the surgical samples from each patient.

\section{Samples collection}

Human NP samples were collected from normal cadavers as control $[\mathrm{n}=10$, average age 36.4 (range 23-50) years, male/female $=5 / 5]$, patients with idiopathic scoliosis as disease control $[\mathrm{n}=10$, average age 26.9 (range 18-36) years, male/female $=5 / 5$ ] and patients with IDD as degenerative NP samples [ $n=10$, average age 40.1 (range 28-55) years, male/female $=5 / 5$ ] as we previously reported[18]. Intervertebral disc specimens were classified as grade I (normal discs), II (idiopathic scoliosis discs) and grade IV (IDD discs) according to MRI manifestation proposed by Pfirrmann and colleagues [19]. All the patients with disc degeneration were strictly selected by MRI and intraoperative findings to exclude NP samples that had herniated outside the annulus. The NP tissues were dissected carefully under magnification.

\section{Transmission Electron Microscopy (TEM)}

Samples of NP and AF were fixed in a mixture of $2 \%$ paraformaldehyde and $2 \%$ glutaraldehyde with phosphate buffer ( $\mathrm{pH} 7.4$ ), subsequently postfixed in a $1 \%$ solution of osmium tetroxide with $1.5 \%$ potassium ferrocyanide. Following being dehydrated in graded alcohols, the samples were embedded in Epon. Ultra-thin sections were prepared and contrasted with uranyl acetate and lead citrate. Sections were studied using electron microscopy JEM 2000 EX (Japan Electron Organization) with an accelerating voltage of 80 $\mathrm{kV}$.

\section{TUNEL assay}

To determine apoptosis in control and IDD samples, we performed TUNEL (Terminal deoxynucleotidyl transferase mediated X-dUTP nick end labeling, TUNEL) assay using the In Situ Cell Death Detection Kit (TMR Red, Roche, Mannheim, Germany). The assay was carried out as described by the manufacturer. Briefly, following dehydrated and proteinase digestion with proteinase $\mathrm{K}$ for $15 \mathrm{~min}, 50$ $\mu$ of TUNEL cocktail was added on the sections. DAPI staining was used as the final step in fluorescent staining procedure to label cell nuclei. The apoptotic cells were analyzed using the fluorescent microscope (excitation: $543 \mathrm{~nm}$; emission: 555-655 nm). The apoptotic index [(number of apoptotic cells/total number counted) $\times 100 \%$ ] was used to quantify the number of TUNEL positive cells. Six nonadjacent fields in each group were randomly chosen to count the total number of NP cells and TUNEL-positive cells.

\section{Pre-digestion of the NP}

NP samples were pre-digested with enzymatic digestion for 40 min at $37{ }^{\circ} \mathrm{C}$ in PBS with $0.25 \%$ pronase (Gibco-BRL, Carlsbad, USA).The pronase containing solution was removed, remaining tissue washed, and digested for $4 \mathrm{~h}$ in PBS with $0.025 \%$ collagenase type II (Invitrogen, Carlsbad, USA).

\section{Flow cytometry (FCM)}

FCM of cells derived from digested NP with Propidium Iodide (PI)/Annexin V double labeling as well as PI staining was performed for apoptosis and cell cycle analysis. PI/Annexin V double staining was performed as described [20]. In brief, after washing twice with PBS, $1 \times 10^{6}$ cells were re-suspended in binding buffer. FITC-Annexin $\mathrm{V}$ was added and then incubated at room temperature for $10 \mathrm{~min}$. PI was 
added and incubated for $15 \mathrm{~min}$ at $4^{\circ} \mathrm{C}$. PI staining for cell cycle analysis was performed in a similar way with incubation for $3 \mathrm{~h}$ at $4^{\circ} \mathrm{C}$. Samples were analyzed on a FACScan (Becton Dickinson, USA).

\section{NP cell culture}

NP cells were pre-digested as aforementioned. The digest was filtered through a $45-\mu \mathrm{m}$ pore size nylon mesh. Cells were plated and expanded for 3 weeks in DMEM/F12-based culture medium (Hyclone, Utah, USA), containing 15\% fetal bovine serum (Gibco-BRL, Carlsbad, USA), 1\% penicillin/streptomycin (Invitrogen, Carlsbad, USA) in a 5\% $\mathrm{CO}_{2}$ incubator. The passage $=1 \mathrm{NP}$ cells were divided into two groups: glucose-free cultured (G0) group: NP cells were planted in glucose-free DMEM/F12-based culture medium (Gibco-BRL, Carlsbad, USA) supplemented with $15 \%$ fetal bovine serum (Gibco-BRL, Carlsbad, USA); and standard cultured (G1) group: NP cells were planted in standard DMEM/F12-based culture medium (Hyclone, Utah, USA) containing $3.151 \mathrm{~g} / \mathrm{L}$ glucose supplemented with $15 \%$ fetal bovine serum (Gibco-BRL, Carlsbad, USA). Culture medium was changed twice a week. NP cells were investigated under inverted microscopy.

\section{Statistical analysis}

Values are noted as means \pm S.E.M. Comparisons of two-group parameters were performed using Student's $t$ test. A $P$ value less than 0.05 was considered as statistically significant. The statistical analysis was performed using the SPSS13.0 statistical package (SPSS Inc., Chicago, IL, USA).

\section{RESULTS}

\section{Human AF and NP cells have a variety of morphology. NP cells with long processes exist in degenerative NP. AF and NP cells have similar morphologic traits. AF and NP cells have the potential as histiocytes.}

As noted previously[2], human disc consisted of sparse AF/NP cells and a large amount of dense ECM, e.g. collagenous fibrils and glycosaminoglycans . The ECM of AF was compact lamellar structure while the ECM of NP was loose and disordered structure (Figure 1A). The collagenous fibrils of normal AF (Figure 1B) were tightly and orderly arranged while the collagenous fibrils of degenerative AF (Figure 1C) were cracked and randomly arranged.

Typical AF cells (Figure 2A) were fibroblast-like, elongated, and aligned parallel to the collagenous fibrils. Typical NP cells (Figure 2B) were small round-shaped chondrocyte-like cells with big indented nucleus. Both of AF and NP cells consisted of endoplasmic reticulum, secretory vesicles, primary and secondary lysosomes, short processes. Similar with the chondrocyte and cartilage lacuna, AF and NP cells (Figure 2A and B) located within the nest, which was made up of ECM and surrounded the cell. We also noted that several AF or NP cells may share one nest (Figure 2C and D).
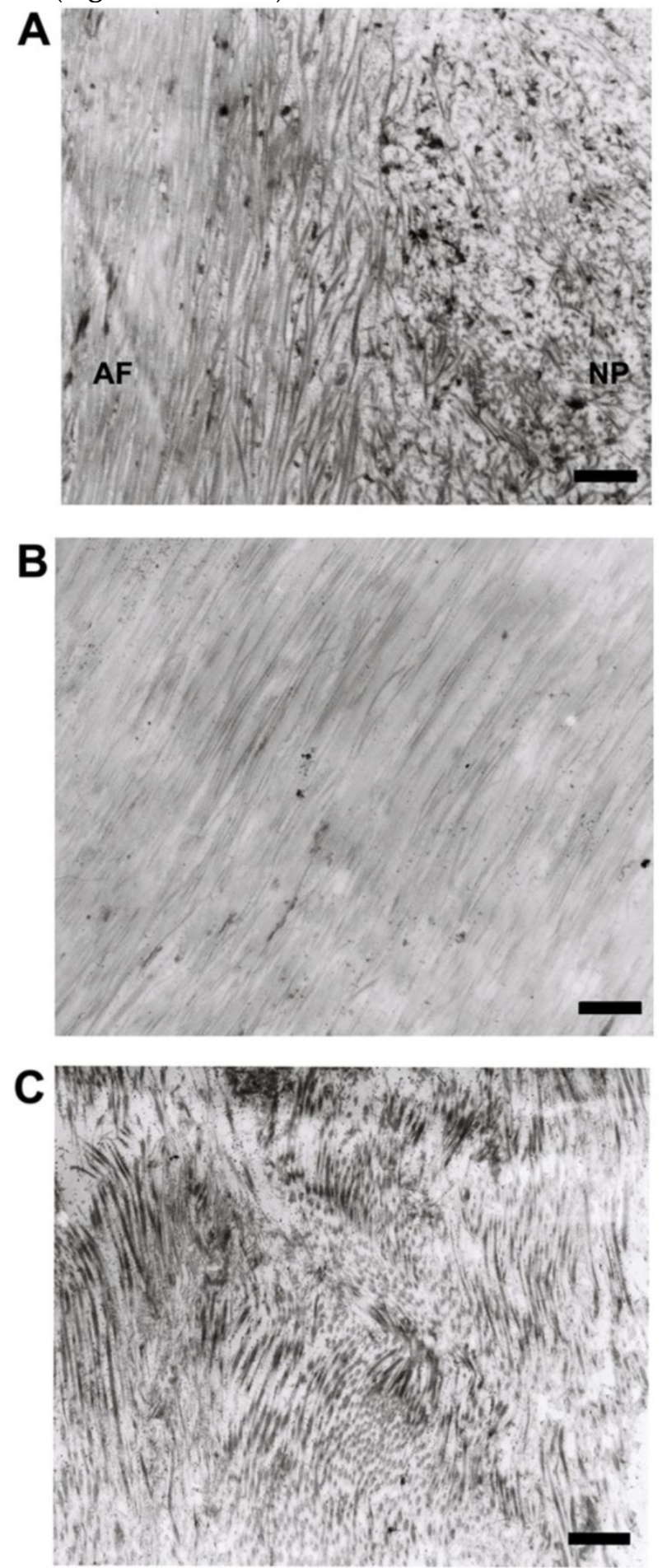

Fig I. Representative microphotographs of extracellular matrix of human disc. (A) The boundary between annulus fibrosus and nucleus pulposus. (B) The collagenous fibrils of normal annulus fibrosus. (C) The collagenous fibrils of degenerative annulus fibrosus. Scale bars: $1 \mu \mathrm{m}$. 
A

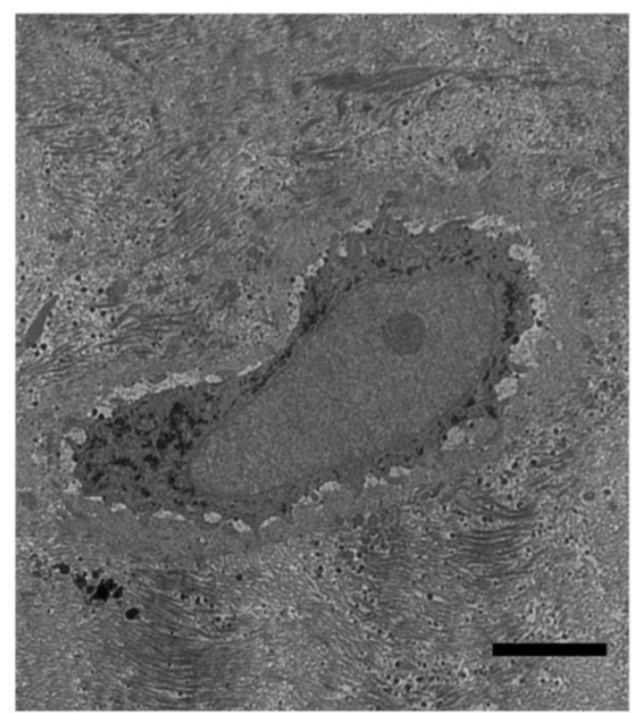

C

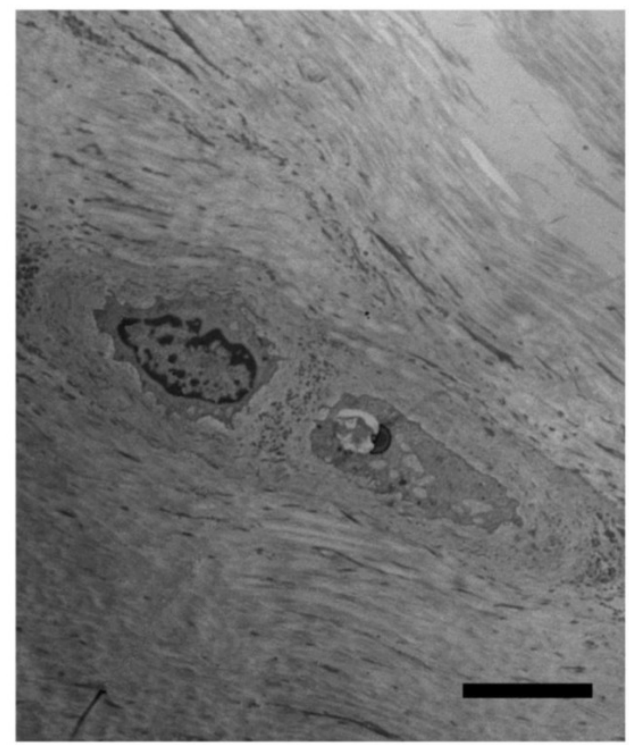

B

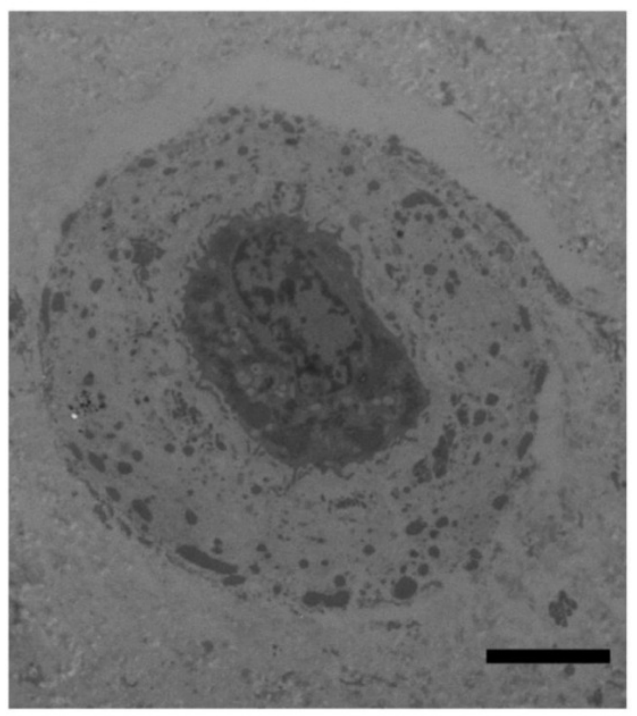

D

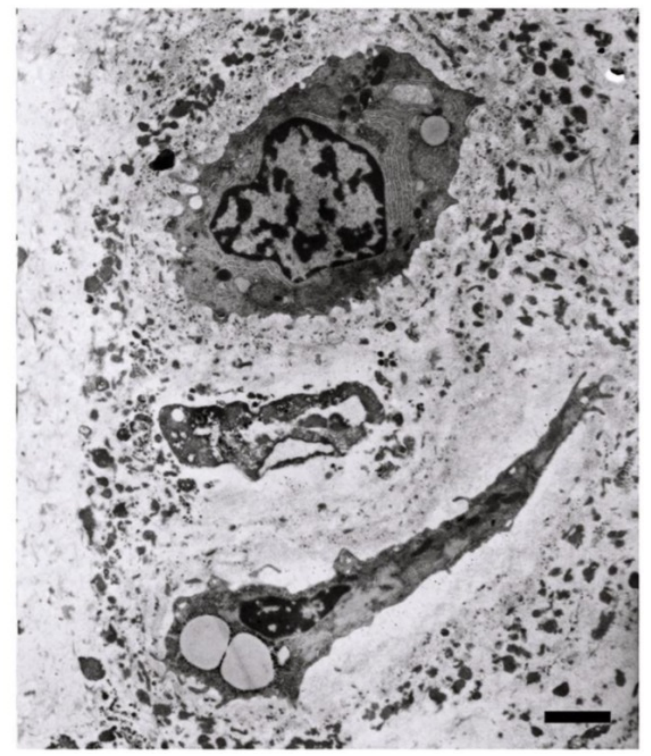

Fig 2. Representative microphotographs of human annulus fibrosus and nucleus pulposus cells. (A) The typical fibroblast-like annulus fibrosus cell within the nest and aligned parallel to the collagenous fibrils. (B) The typical chondrocyte-like nucleus pulposus cell within the nest and surrounding dense extracellular matrix. (C) Two annulus fibrosus cells located in one nest. (D) Three nucleus pulposus cells located in one nest. Scale bars: (A)-(C) $5 \mu \mathrm{m}$; (D) $\mathrm{I} \mu \mathrm{m}$.

While necrotic and apoptotic NP cells (Figures 3A and B) were detected, degenerative NP consisted mainly of viable NP cells. Viable NP cells were further categorized into typical NP cells (Figure 2B), NP cells with long processes (Figure $3 \mathrm{C}$ and $\mathrm{D}$ ), and phagocytic NP cells (Figure 4) in terms of morphology and the number and type of cytoplasm. The cytoplasm of phagocytic NP cells was consisted of large amount of endoplasmic reticulum and lysosomes, while the cytoplasm of typical NP cells and NP cells with long processes was consisted of less lysosomes. NP cells with long processes were found both in degenerative
(Figure 3C) and in disease control discs (Figure 3D) rather than normal discs.

Phagocytic NP cells had the hallmarks of both stationary macrophages with lysosomes (histiocytes) and NP cells with a large amount of the endoplasmic reticulum (Figure $\mathbf{4 A}$ and $\mathrm{B}$ ). The appearance of primary and secondary lysosomes reflects the functional activity of phagocytic NP cells (Figure 4C) and AF cells (Figure 5A-C). Lipofuscin, the residues of lysosomal digestion, was found in AF cells (Figure 5D). Importantly, we identified NP cell that undergoing phagocytosis in NP tissues (Figure 4D). 


\section{A}

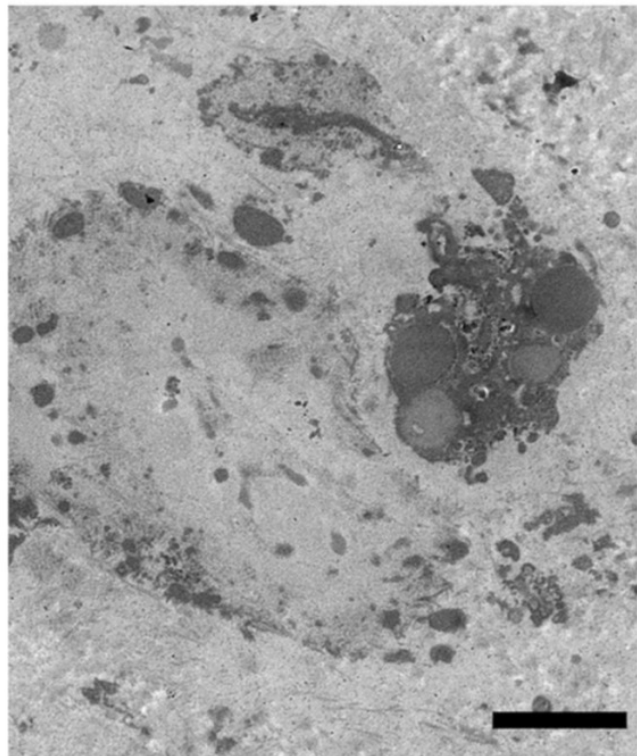

\section{C}

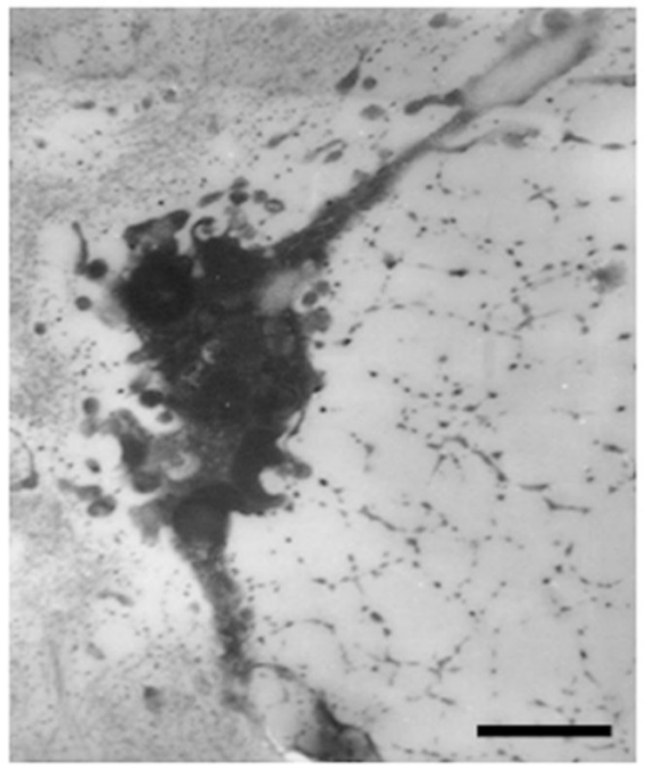

B
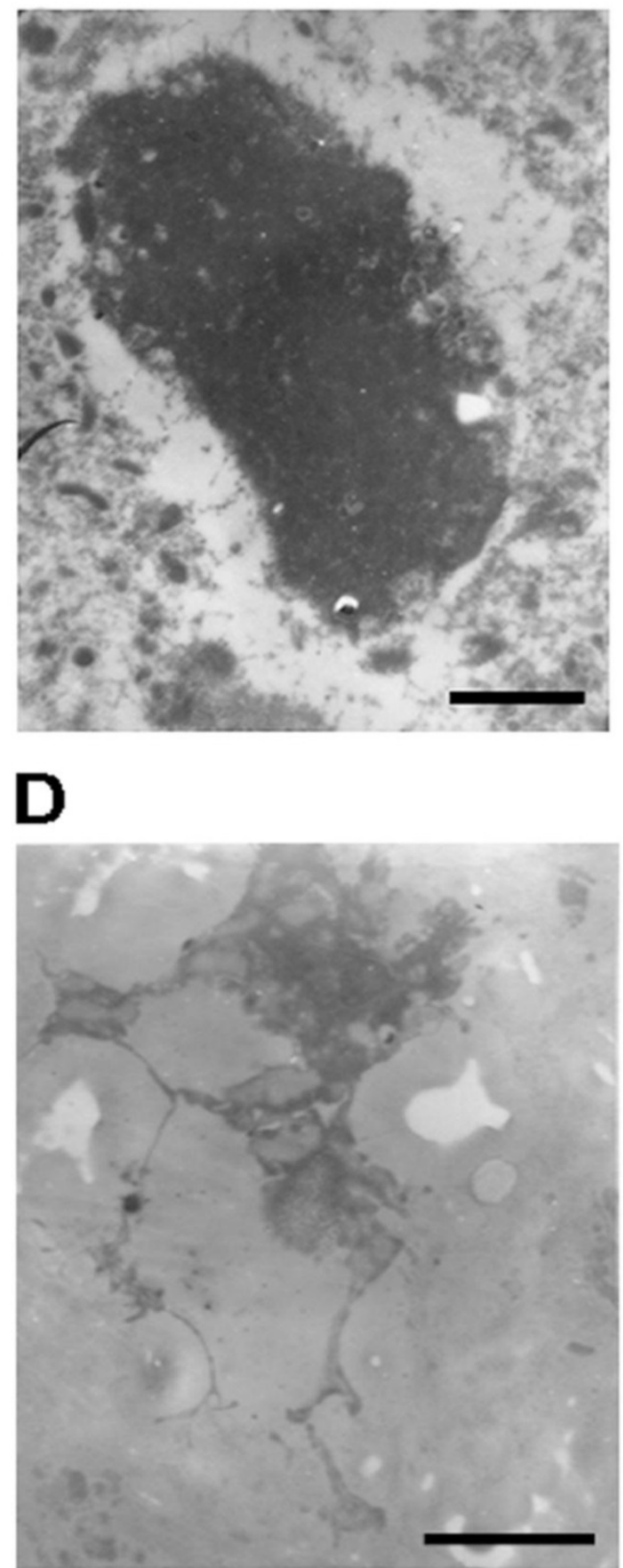

Fig 3. Representative microphotographs of necrotic human nucleus pulposus cells and human nucleus pulposus cells with long cell processes. (A) The necrotic nucleus pulposus cell with incomplete cellular membrane. (B) The necrotic nucleus pulposus cell within the nest. (C) The nucleus pulposus cell with long processes from degenerative disc. Note the secretory vesicles within the cell. (D) The nucleus pulposus cell with long processes from scoliosis disc. Scale bars: (A) $3 \mu \mathrm{m}$; (B)-(D) $500 \mathrm{~nm}$. 


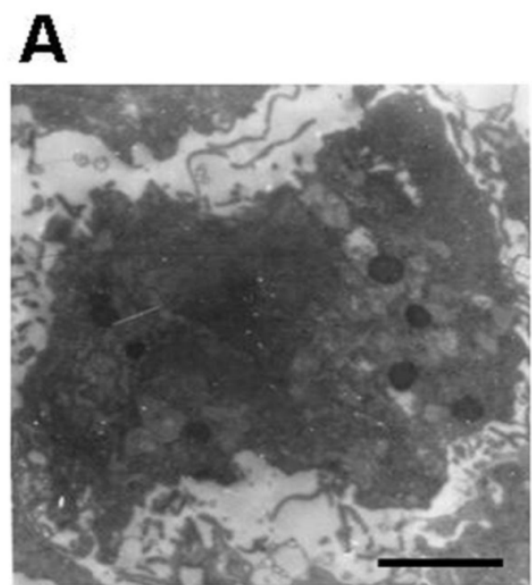

\section{B}

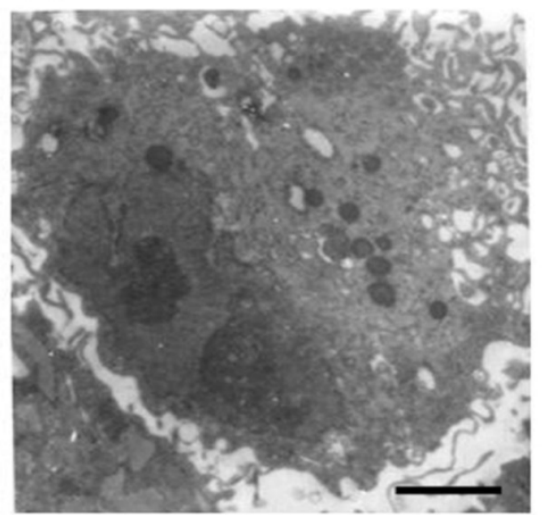

C
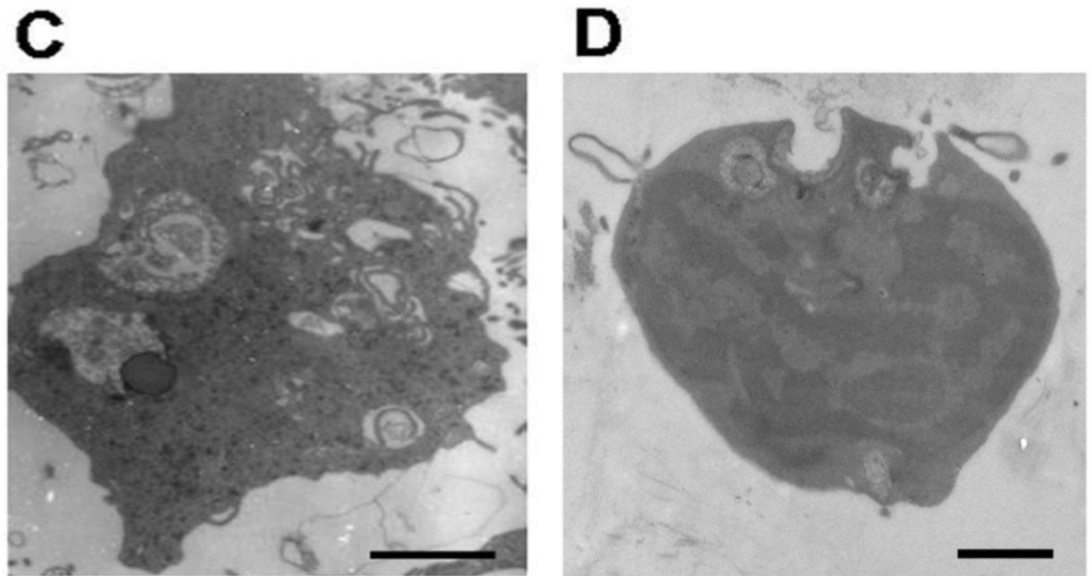

Fig 4. Representative microphotographs of phagocytic nucleus pulposus cells. (A) and (B) Phagocytic nucleus pulposus cells with a large amount of endoplasmic reticulum and lysosomes. (C) The phagocytic nucleus pulposus cell with secondary lysosomes. (D) Nucleus pulposus cell that undergoing phagocytosis. Scale bars: I $\mu \mathrm{m}$

A

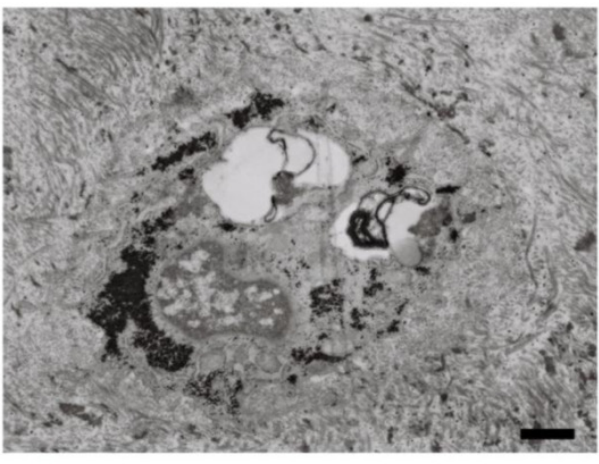

C

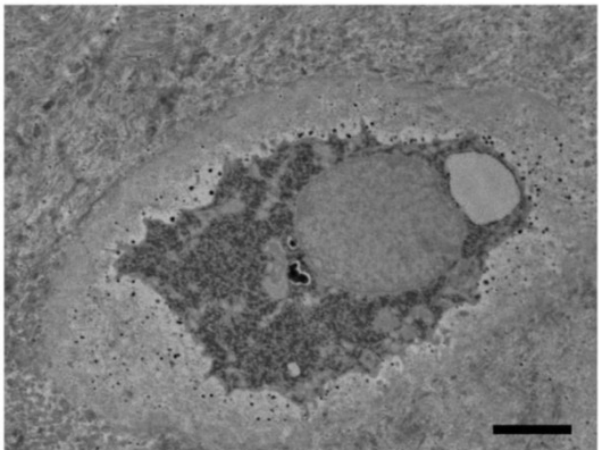

B

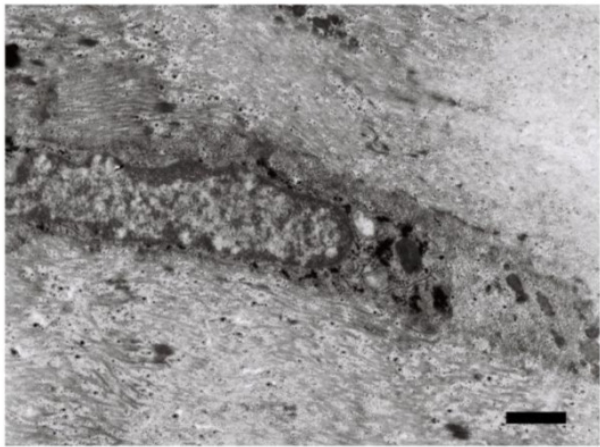

D

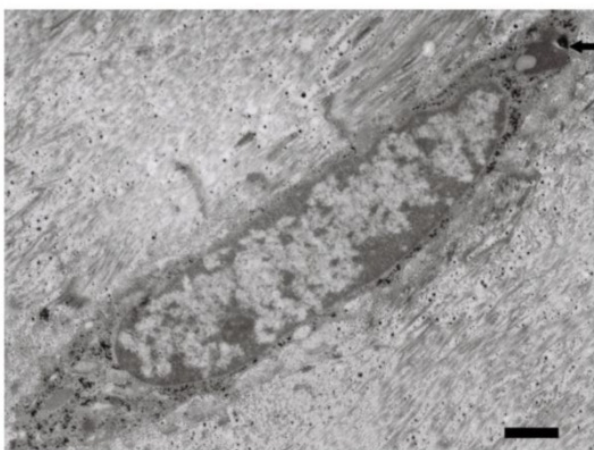

Fig 5. Representative microphotographs of phagocytic annulus fibrosus cells. (A)-(C) Phagocytic annulus fibrosus cells with primary and secondary lysosomes. (D) Phagocytic annulus fibrosus cells with secondary lysosomes next to lipofuscin (black arrow). Scale bars: (A), (B) and (D) I $\mu \mathrm{m}$; (C) $3 \mu \mathrm{m}$ 


\section{Human NP consists of mainly viable cells. Apoptosis increases in degenerative NP.}

Consistent with the results of TEM, FCM revealed that human NP was composed predominantly of viable cells (Figure 6A, $87.42 \pm 1.13 \%$ ), even in degenerative NP $(83.27 \pm 5.00 \%, P>0.05$, Figure 6B, C). Apoptosis of degenerative NP increased in comparison with control NP $(6.80 \pm 0.93 \% ; 5.03 \pm 1.82 \%, P<0.05)$. In addition, cells of digested NP remained proliferate and in cell-cycle homeostasis (Figure 6D).

In accordance with the FCM results, TUNEL assay indicated only very few TUNEL-positive NP cells were noted in control NP. In contrast, there was an apparent increase in the number of apoptotic NP cells in degenerative NP (Apoptotic Index: 32.54 \pm 2.25 in control NP versus $63.75 \pm 2.98$ in degenerative NP, $P<0.01$ ) (Figure 7).

\section{Human NP cells undergo morphologic varia- tion with in vitro monolayer cultures}

Human NP cells maintained their round-shape within the several days following monolayer culture. Cell clusters were noted and then diminished gradually in vitro. Colony formation and heterogeneous cellular composition were noted for primarily cultured human NP cells (Figure 8A). However, NP cells lost their round-shape at this stage. Furthermore, they underwent morphologic alterations gradually with passages (Figure $\mathbf{8 B}, \mathbf{C}$ ), in particular the long spindle NP cells with cultures over four weeks (passage $=3$, Figure $8 \mathrm{D}$ ). The morphologic variety might reflect the changes of NP cells in phenotype and the trends towards senescence. Compared with the G1 group, the NP cells in G0 group developed long and thin cell processes when cultured in 3, 6, 9 days (Figure 9). Stellate cells with multiple long and thin processes were noted.
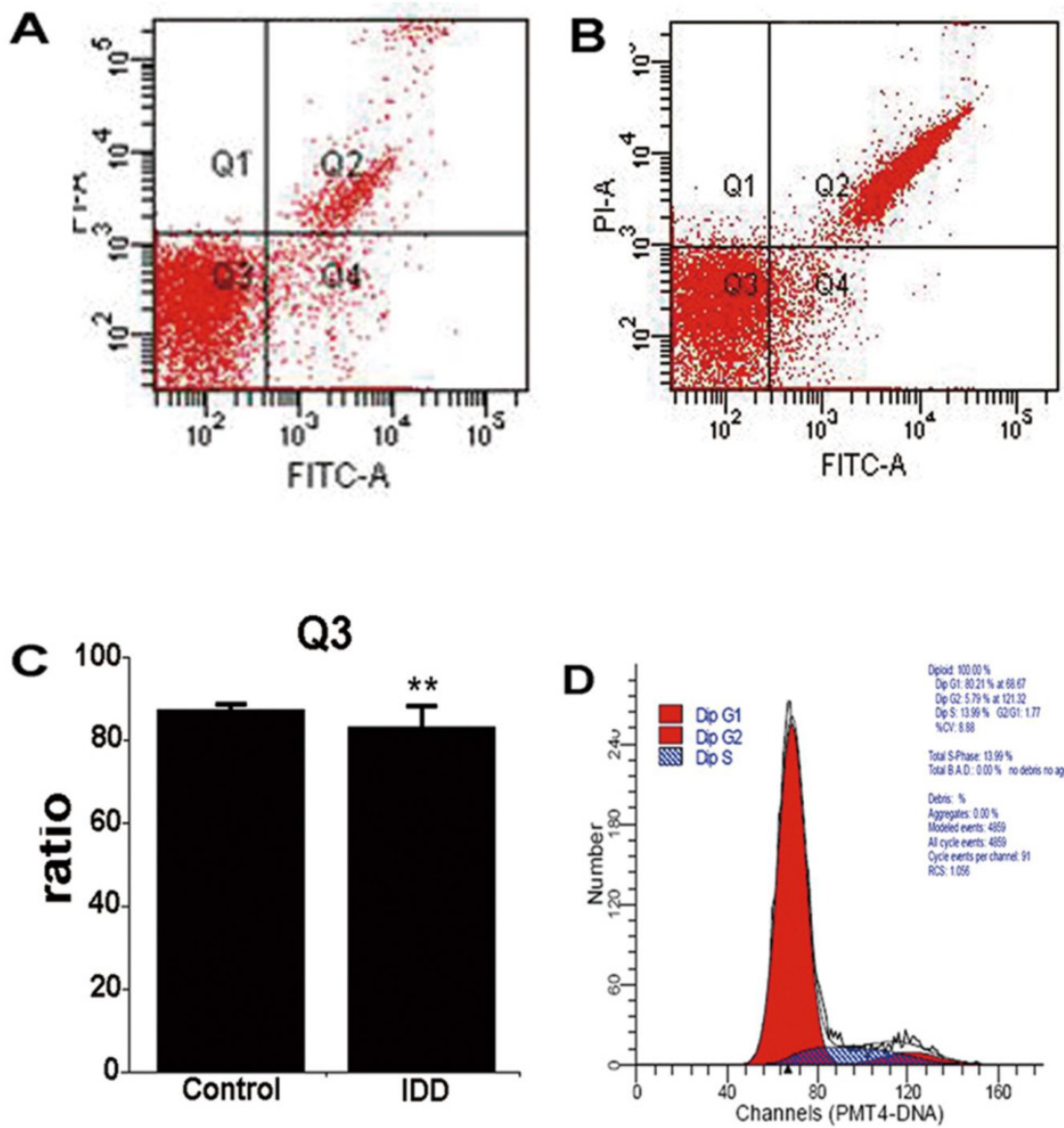

Fig 6. Contour diagram of FITC-Annexin V/PI FCM of human digested nucleus pulposus. Diagram of nucleus pulposus derived from scoliosis and IDD corresponds to control and disease. (A) and (B), Representative diagram of control and degenerative nucleus pulposus. Q3 shows the viable cells (PI-/FITC-). Q2 consists of the non-viable cells, including necrotic and late phase of apoptotic cells (PI+/FITC+). Q4 represents the apoptotic cells in early phase with cytoplasmic membrane integrity (PI-/FITC+). (C) nucleus pulposus consists of mainly viable cells. ${ }^{*} P>0.05$. (D) The cell cycle diagram suggests that digested nucleus pulposus has a profile of normal cells with homeostasis. 


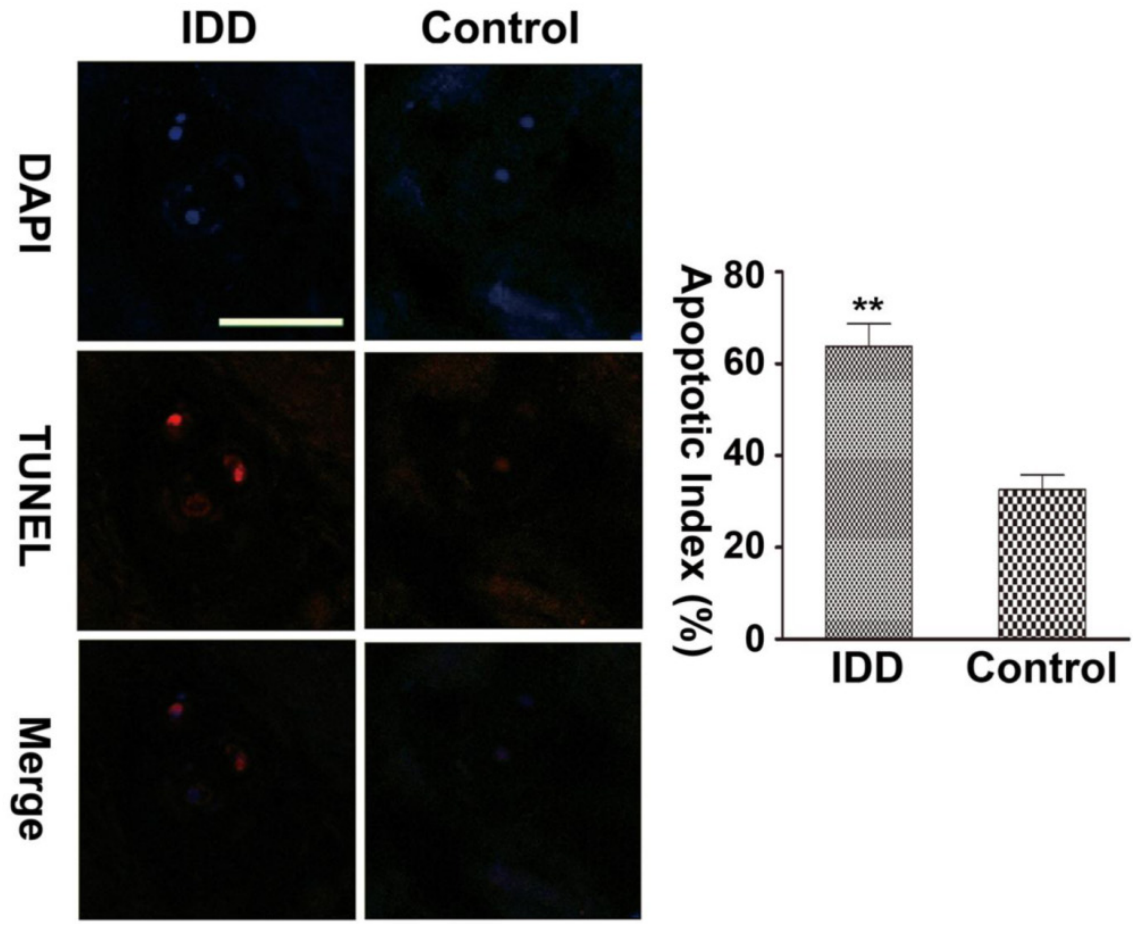

Fig 7. Representative microphotographys of TUNEL assay in control and IDD nucleus pulposus. Only few TUNEL-positive cells were detected in control nucleus pulposus, whereas increased number of TUNEL-positive cells was noted in degenerative nucleus pulposus. Scale bars: $50 \mu \mathrm{m}$. Apoptotic index of NP cells was calculated as mean \pm SD. Apoptotic index: $63.75 \pm 2.98$ in degenerative NP versus $32.54 \pm 2.25$ in control NP, $* * P<0.0$ I versus control group, $n=5$.
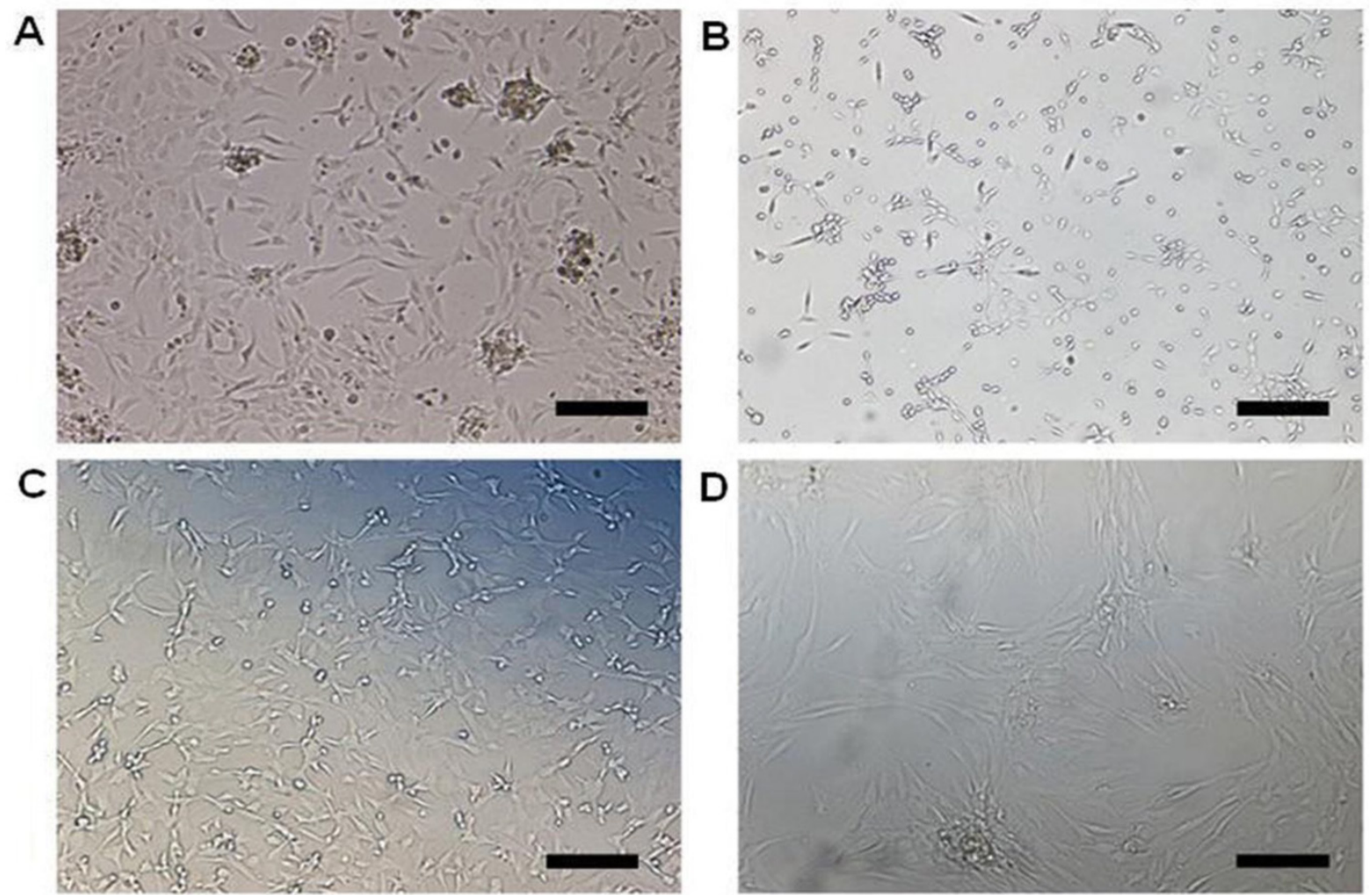

Fig 8. Representative microphotography of cultured human nucleus pulposus cells. (A) Primarily cultured human nucleus pulposus cells (passage $=0$, I Id after culture) with colony formation and heterogeneous cellular composition under inverted microscopy. (B-D) Cultured human nucleus pulposus cells (passage =I, 2, 3; 16d, 23d, 29d after culture) showing the alterations of nucleus pulposus cells with passages under inverted microscope. The cultured NP cells in (A-D) were obtained from the L5/SI nucleus pulposus of a 28 -year-old male with disc degeneration classified as grade IV. Scale bars: $50 \mu \mathrm{m}$. 

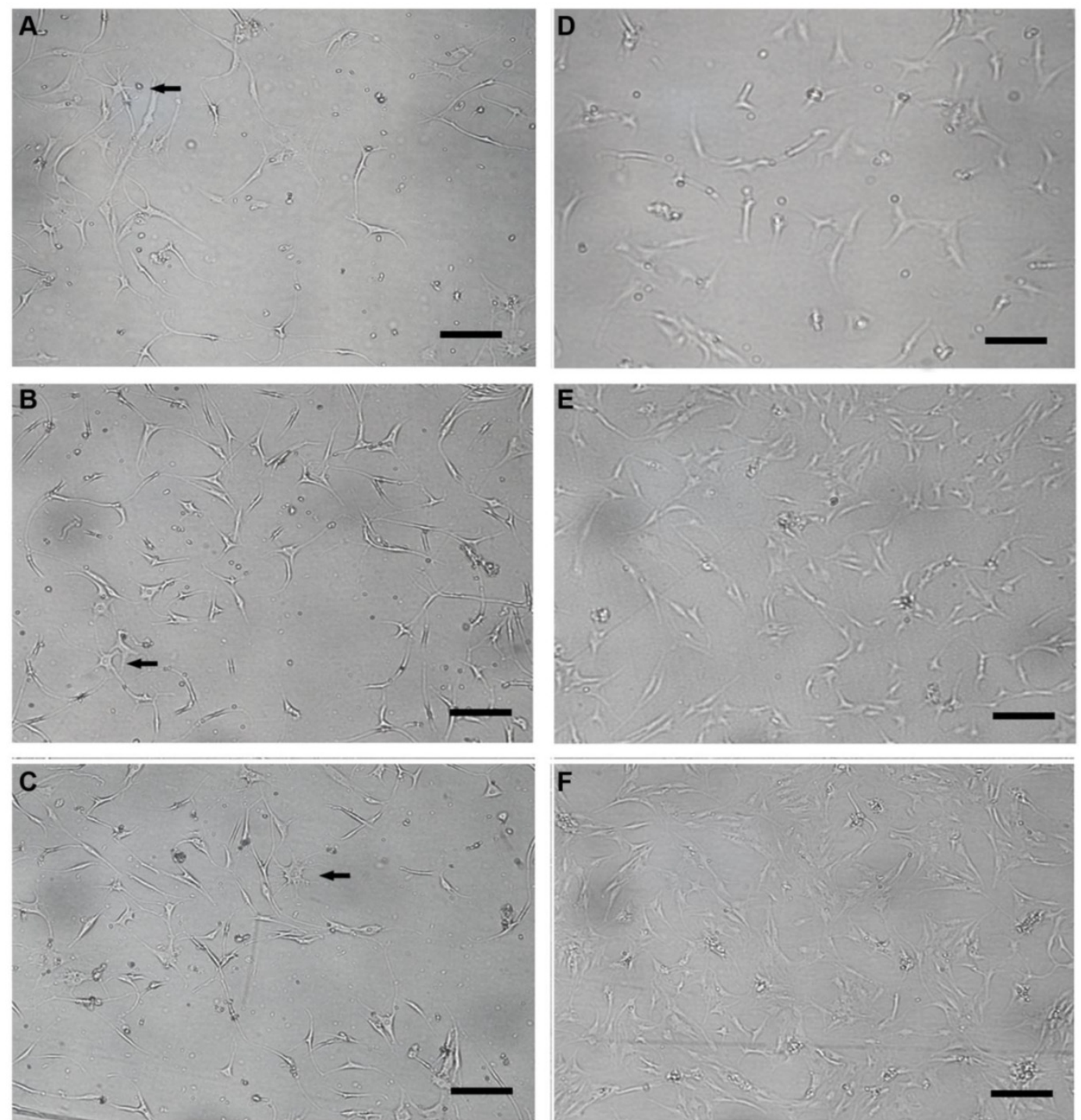

Fig 9. Representative microphotography of cultured human nucleus pulposus cells in glucose- free and standard DMEM/FI2-based culture medium. (A-C) Glucose- free group nucleus pulposus cells (3d, 6d, 9d after culture) with long and thin processes; stellate cells with multiple processes were noted (black arrow). (D-F) Cell processes of nucleus pulposus cells in standard DMEM/FI2-based culture medium group (3d, 6d, 9d after culture) were relatively shorter. Scale bars: $30 \mu \mathrm{m}$.

\section{DISCUSSION}

The abnormality of NP cells, the major component cells of intervertebral disc, is believed to play a vital role in IDD. Here, we found that degenerative NP cells were predominantly viable cells with phagocytic potential, and AF cells had the similar phagocytic function as NP cells. Moreover, NP cells with long processes were identified in NP from IDD and scoliosis rather than normal NP. Our morphologic findings present new insights into human NP, clarifying several debating issues related to cell death occurrence, apoptosis or necrosis as forms of cell death, NP cells as phagocytes and NP cells with long processes.

First, our findings reveal that most cells are viable NP cells within control and degenerative discs, which was inconsistent with the traditional view of point $[2,10,21,22]$. Previous studies have reported that cell death within the disc is common, ranging from over $50 \%$ (detected by electron microscope) [2] to $73 \%$ (detected by TUNEL assay) [16]. Nevertheless, the question remains open as to whether or not apoptosis or necrosis exists within the disc. Consistent with the view of Johnson and colleagues [17], our results present direct and sufficient evidence demonstrating that even degenerative NP might have the capability of maintaining homeostasis of cell population.

Second, our results present direct morphologic evidence that human NP cells have multiple potential. Aside from building and sweeping extracellular matrix, NP cells can also phagocytose nonviable NP cells as phagocytic cells. The fact that phagocytic NP cells 
displayed morphologic hallmarks of both NP cells and macrophages indicates that the cells belong to histiocytes. In combination with the characteristic of blood supply of NP, we might exclude the possibility of invaded mononuclear macrophages from peripheral blood vessels. In this respect, Nerlich and colleagues reported phagocytic cells in human degenerative NP with CD68 positive staining and no morphologic difference from NP cells under microscopy [14]. In accordance with our findings, they named these cells as transformed resident cells. Furthermore, our finding of in vivo phagocytic NP cells complements the in vitro evidence of NP cells as competent phagocytes noted by Jones and colleagues [10]. In other parts of the human body, macrophages might fuse to form multi-nuclear giant cells following phagocytosis, i.e., Langerhans cells. Previously, cell clusters formation is noted as one of the hallmarks of disc degeneration and cell proliferation [7], the mechanism of which remains unknown. In combination of our findings, a plausible explanation for cell clusters might be the fusion of phagocytic NP cells as a result of phagocytosis.

Third, our study provides direct evidence that AF cells have similar morphologic traits with NP cells as belows. $a$. both of AF and NP cells are located within cell nests. $\boldsymbol{b}$. Several cells may share one nest. $\boldsymbol{c}$. Both AF and NP cells consist of endoplasmic reticulum, secretory vesicles, short processes. $\boldsymbol{d}$. Lysosomes frequently appear in both AF and NP cells, which indicates that AF cells have similar phagocytic function with that of NP cells. There has been long-lasting debate concerning the origin of NP cells, which yet remains enigmatic. Increasing evidence sustains that NP consists of notochordal cells in fetus. As the disc matures, notochordal cells are replaced by smaller chondrocyte-like cells with an assumed different origin[23]. From this point of view, it is deducible that NP might recruit cells from AF. Several lines of evidence indicate that both the morphology and phenotype of NP and AF cells are interchangeable on different culture conditions: NP cells in monolayer might convert from round-shaped cells into fibroblast-like cells, from rich in type-II collagen to type-I collagen. Conversely, AF cells cultured in 3D environment could convert into chondrocyte-like cells with increased type-II collagen production and SOX-9 expression[24, 25]. Furthermore, there would be no significant differences in gene expression or protein production between NP and AF cells in either monolayer or 3D culture environment following 2 weeks in vitro culture [26]. Moreover, it has been noted that in adult, endplate chondrocytes and inner AF cells give rise to chondrocyte-like cells at the same time replacing notochord-derived large vacuolated cells in NP
[27]. Our study supplements the assumed origin of human NP cells. Accordingly, it would be reasonable to assume that the NP cells and AF cells might be from identical lineages in adults.

Fourth, previous studies designate NP cells with long processes as a hallmark of NP cells derived from deformed discs, which include discs with scoliosis and spondylolisthesis [6]. However, NP cells with long processes are also noted in degenerative NP without deformation on the basis of our findings, which might cast doubt on the previously assumed mechanism of abnormal load subjected to the disc [5]. Moreover, our study found that the deprivation of glucose in culture medium directly led to the formation of similarly long cell processes when NP cells were in vitro cultured. It has been shown that glucose deprivation leads to the acceleration of disc degeneration and fall in NP cell viability[28, 29], and the collapse of nutrition supply pathway of NP is a well-accepted pathogenesis factor of IDD. We proposed that the lack of glucose may be one of the underlying mechanisms of long process formation. Therefore, it might be reasonable that long process cells exist in degenerative NP as well, but not exclusively exist in deformed discs. Nevertheless, the accurate mechanisms of long processes formation remain to be defined.

In parallel with in vivo studies of the NP, in vitro NP cell cultures present an important approach for addressing the cell biology of the NP. Various NP cells with diverse cell markers and phenotypes derived from different species have been cultured and studied, which include rabbit [30], canine [31, 32], bovine [10, 33], rat [34, 35] and human [36-38]. Amongst the species, bovine NP is closest to human $\mathrm{NP}$ in terms of cell phenotype [33, 39]. On the other hand, various cell markers were reported in diverse species, including CD24 (human and Wistar rat) [34], CD44 (rat) [40], Galectin-3 (human) [41], SOX-9 and collage II (human) [4], HIF-1, GLUT-1 an MMP-2 (rat) [42]. Moreover, monolayer as well as 3D cultures [37, 38] with a multitude of scaffolds, even organ cultures of the disc [43-46] have been addressed. However, there is relative paucity of information regarding the details of human NP cells' morphologic variation with cultures. At this point, our delineation of the hallmarks of NP cells under cultures might shed new light on the knowledge of human NP cells.

It has been noted that human NP has the hallmark of immune privilege, owing to the avascular settings as well as the local expression of FasL [47-50]. Moreover, FasL expression on the NP begins in early embryo [35]. However, the question remains open as to whether or not the immune privilege of the degenerative NP is preserved. On the basis of our findings, 
human NP cells have phagocytic potential to possibly clear apoptotic/necrotic cells and ruptured ECM, and ultimately contribute to the maintenance of immune privilege [51]. At this point, additional studies are needed to further define the immune privilege following IDD.

In spite of our study presented novel lines of evidence that expand our understanding of human NP cells and IDD, several limitations were present. For one, we pre-digested human NP tissues prior to FCM analysis. The pre-digestion with pronase and collagenase might influence the number of cell death. However, both the control and IDD samples consisted of primarily viable cells following the same digestion procedure, which might preclude the impact of digestion. Nevertheless, the possible impact of digestion on tissues might be the increase of cell death. At this sense, the pre-digested NP cells might consist of more dead cells. While the results exclude the possibility. On the other hand, the pre-digestion procedure is similar with the procedure with which we collect cultured cells in cell plates for FCM, which is a procedure with possible unexpected impact but essential.

In conclusion, human degenerative NP consists of primarily viable cells. We present direct and in vivo evidence that both human annulus fibrosus and NP cells have phagocytic potential. Moreover, NP cells with long processes exist in both scoliotic and degenerative NP with lack of glucose as one of the possible underlying mechanisms. Together, these novel insights into the hallmarks of human NP cells might shed light on our understanding of disc cell biology and degeneration.

\section{Acknowledgement}

We thank our clinical staff for helping obtain specimens; our office secretary Dan Geng and Li-Feng Lan for their coordination of the experimentation and assistance in cell cultures. This study was supported by the Chinese National Natural Science Foundation Project $(81270028,30901509$ and 81171747).

\section{Authors' contributions}

ZJL, HQW, YFC conceived of the study, participated in the design of the study and performed the statistical analyses. All authors carried out the experiments. HQW drafted the manuscript with the help of DS and YFC. All authors have read and approved the final manuscript.

\section{Competing Interests}

The authors have declared that no competing interest exists.

\section{References}

1. Hayes AJ, Benjamin M, Ralphs JR. Extracellular matrix in development of the intervertebral disc. Matrix Biology. 2001; 20: 107-21.

2. Trout JJ, Buckwalter JA, Moore KC. Ultrastructure of the human intervertebral disc: II. Cells of the nucleus pulposus. Anat Rec. 1982; 204: 307 - 14

3. Hunter CJ, Matyas JR, Duncan NA. The notochordal cell in the nucleus pulposus: a review in the context of tissue engineering. Tissue engineering. 2003; 9: 667-77. doi:10.1089/107632703768247368.

4. Sive JI, Baird P, Jeziorsk M, Watkins A, Hoyland JA, Freemont AJ. Expression of chondrocyte markers by cells of normal and degenerate intervertebral discs. Mol Pathol. 2002; 55: 91-7. doi:10.1136/mp.55.2.91.

5. Roberts S, Evans $\mathrm{H}$, Trivedi J, Menage J. Histology and pathology of the human intervertebral disc. J Bone Joint Surgery Am. 2006; 88: 10-4. doi:10.2106/jbjs.f.00019.

6. Johnson $\mathrm{WE}$, Roberts $\mathrm{S}$. Human intervertebral disc cell morphology and cytoskeletal composition: a preliminary study of regional variations in health and disease. J Anat. 2003; 203: 605-12.

7. Johnson WE, Eisenstein SM, Roberts S. Cell cluster formation in degenerate lumbar intervertebral discs is associated with increased disc cell proliferation. Connective tissue research. 2001; 42: 197-207.

8. Bibby SR, Fairbank JC, Urban MR, Urban JP. Cell viability in scoliotic discs in relation to disc deformity and nutrient levels. Spine (Phila Pa 1976). 2002; 27: 2220-8; discussion 7-8.

9. Sive JI, Baird P, Jeziorsk M, Watkins A, Hoyland JA, Freemont AJ. Expression of chondrocyte markers by cells of normal and degenerate intervertebral discs. Mol Pathol. 2002; 55: 91-7.

10. Jones P, Gardner L, Menage J, Williams G, Roberts S. Intervertebral disc cells as competent phagocytes in vitro: implications for cell death in disc degeneration. Arthritis Res Ther. 2008; 10: R86.

11. Gan JC, Ducheyne P, Vresilovic EJ, Swaim W, Shapiro IM. Intervertebral disc tissue engineering I: characterization of the nucleus pulposus. Clin Orthop Relat Res. 2003;: 305-14. doi:10.1097/01.blo.0000063796.98363.9a.

12. Grunhagen T, Wilde G, Soukane DM, Shirazi-Adl SA, Urban JPG. Nutrient supply and intervertebral disc metabolism. J Bone Joint Surgery Am. 2006; 88: 30-5. doi:10.2106/jbjs.e.01290.

13. Kawaguchi S, Yamashita T, Yokogushi K, Murakami T, Ohwada O, Sato N. Immunophenotypic analysis of the inflammatory infiltrates in herniated intervertebral discs. Spine (Phila Pa 1976). 2001; 26: 1209-14.

14. Nerlich AG, Weiler C, Zipperer I, Narozny M, Boos N. Immunolocalization of phagocytic cells in normal and degenerated intervertebral discs. Spine (Phila Pa 1976). 2002; 27: 2484-90.

15. Gruber HE, Hanley EN. Recent advances in disc cell biology. Spine (Phila Pa 1976). 2003; 28: 186-93

16. Gruber HE, Hanley EN, Jr. Analysis of aging and degeneration of the human intervertebral disc. Comparison of surgical specimens with normal controls. Spine (Phila Pa 1976). 1998; 23: 751-7.

17. Johnson $\mathrm{WE}$, Roberts $\mathrm{S}$. Rumours of my death may have been greatly exaggerated': a brief review of cell death in human intervertebral disc disease and implications for cell transplantation therapy. Biochemical Society transactions. 2007; 35: 680-2.

18. Wang HQ, Yu XD, Liu ZH, Cheng X, Samartzis D, Jia LT, et al. Deregulated miR-155 promotes Fas-mediated apoptosis in human intervertebral disc degeneration by targeting FADD and caspase-3. J Pathology. 2011; DOI: 10.1002/path.2931.

19. Pfirmann CWA, Metzdorf A, Zanetti M, Hodler J, Boos N. Magnetic resonance classification of lumbar intervertebral disc degeneration. Spine (Phila Pa 1976). 2001; 26: 1873-8.

20. Vermes I, Haanen C, Steffens-Nakken H, Reutelingsperger C. A novel assay for apoptosis. Flow cytometric detection of phosphatidylserine expression on early apoptotic cells using fluorescein labelled Annexin V. Journal of immunological methods. 1995; 184: 39-51.

21. Chen B, Fellenberg J, Wang H, Carstens C, Richter W. Occurrence and regional distribution of apoptosis in scoliotic discs. Spine (Phila Pa 1976). 2005; 30: 519-24

22. Boos N, Weissbach S, Rohrbach H, Weiler C, Spratt KF, Nerlich AG. Classification of age-related changes in lumbar intervertebral discs. Spine (Phila Pa 1976). 2002; 27: 2631 - 44

23. Risbud MV, Schaer TP, Shapiro IM. Toward an Understanding of the Role of Notochordal Cells in the Adult Intervertebral Disc: From Discord to Accord. DEVELOPMENTAL DYNAMICS. 2010: 2141-8.

24. Richardson SM, et al. Intervertebral disc biology, degeneration and novel tissue engineering and regenerative medicine therapies. Histol Histopathol. 2007; 22: 1033-41.

25. Ciapetti G, et al. Ex vivo observation of human intervertebral disc tissue and cells isolated from degenerated intervertebral discs. Eur Spine J 2012; Suppl 1: S10-S9.

26. Chou AI, Reza AT, Nicoll SB. Nicoll. Distinct Intervertebral Disc Cell Populations Adopt Similar Phenotypes in Three-Dimensional Culture. Tissue Eng Part A. 2008; 14: 2079-87.

27. Shapiro MVRaIM. Notochordal Cells in the Adult Intervertebral Disc: New Perspective on an Old Question. Crit Rev Eukaryot Gene Expr. 2011; 21: 1-16.

28. Rinkler C HF, Pedro MT, Mauer UM, Ignatius A, Neidlinger-Wilke C. Influence of low glucose supply on the regulation of gene expression by 
nucleus pulposus cells and their responsiveness to mechanical loading. J Neurosurg Spine. 2010 13: 535-42.

29. Bibby SR UJ. Effect of nutrient deprivation on the viability of intervertebral disc cells. Eur Spine J. 2004; 13: 695-701.

30. Gan JC, Ducheyne P, Vresilovic EJ, Shapiro IM. Intervertebral disc tissue engineering II: cultures of nucleus pulposus cells. Clin Orthop Relat Res. 2003;: 315-24. doi:10.1097/01.blo.0000063797.98363.d3.

31. Maldonado BA, Oegema TR, Jr. Initial characterization of the metabolism of intervertebral disc cells encapsulated in microspheres. J Orthop Res. 1992; 10: 677-90.

32. Masuda K, Miyabayashi T, Meachum SH, Eurell TE. Proliferation of canine intervertebral disk chondrocytes in three-dimensional alginate microsphere culture. The Journal of veterinary medical science / the Japanese Society of Veterinary Science. 2002; 64: 79-82.

33. Bibby SRS, Urban JPG. Effect of nutrient deprivation on the viability of intervertebral disc cells. Euro Spine J. 2004; 13: 695-701.

34. Fujita N, Miyamoto T, Imai J-i, Hosogane N, Suzuki T, Yagi M, et al. CD24 is expressed specifically in the nucleus pulposus of intervertebral discs. Biochemical and Biophysical Research Communications. 2005; 338: 1890-6.

35. Inui $\mathrm{Y}$, Nishida $\mathrm{K}$, Doita $\mathrm{M}$, Takada $\mathrm{T}$, Miyamoto $\mathrm{H}$, Yoshiya $\mathrm{S}$, et al. Fas-Ligand expression on nucleus pulposus begins in developing embryo. Spine (Phila Pa 1976). 2004; 29: 2365-9.

36. Vadala G, Studer RK, Sowa G, Spiezia F, Iucu C, Denaro V, et al. Coculture of bone marrow mesenchymal stem cells and nucleus pulposus cells modulate gene expression profile without cell fusion. Spine (Phila Pa 1976). 2008; 33: 870-6. doi:10.1097/BRS.0b013e31816b461900007632-200804150-00008 [pii].

37. Sakai D, Mochida J, Iwashina T, Watanabe T, Suyama K, Ando K, et al. Atelocollagen for culture of human nucleus pulposus cells forming nucleus pulposus-like tissue in vitro: influence on the proliferation and proteoglycan production of HNPSV-1 cells. Biomaterials. 2006; 27: 346-53.

38. Le Maitre C, Frain J, Millward-Sadler J, Fotheringham AP, Freemont AJ, Hoyland JA. Altered integrin mechanotransduction in human nucleus pulposus cells derived from degenerated discs. Arthritis Rheum. 2009; 60: 460-9.

39. Horner HA, Roberts S, Bielby RC, Menage J, Evans H, Urban JP. Cells from different regions of the intervertebral disc: effect of culture system on matrix expression and cell phenotype. Spine (Phila Pa 1976). 2002; 27: 1018-28.

40. Stevens JW, Kurriger GL, Carter AS, Maynard JA. CD44 expression in the developing and growing rat intervertebral disc. Dev Dynam. 2000; 219: 381-90.

41. Gotz W, Kasper M, Miosge N, Hughes RC. Detection and distribution of the carbohydrate binding protein galectin-3 in human notochord, intervertebral disc and chordoma. Differentiation 1997; 62: 149-57.

42. Rajpurohit R, Risbud M, Ducheyne P, Vresilovic E, Shapiro I. Phenotypic characteristics of the nucleus pulposus: expression of hypoxia inducing factor-1, glucose transporter-1 and MMP-2. Cell Tissue Res. 2002; 308: 401-7.

43. Lim TH, Ramakrishnan PS, Kurriger GL, Martin JA, Stevens JW, Kim J, et al. Rat spinal motion segment in organ culture: a cell viability study. Spine (Phila Pa 1976). 2006; 31: 1291-7; discussion 8.

44. Risbud MV, Izzo MW, Adams CS, Arnold WW, Hillibrand AS, Vresilovic EJ, et al. An organ culture system for the study of the nucleus pulposus: description of the system and evaluation of the cells. Spine (Phila Pa 1976). 2003; 28: 2652-8; discussion 8-9.

45. Lee CR, Iatridis JC, Poveda L, Alini M. In vitro organ culture of the bovine intervertebral disc: effects of vertebral endplate and potential for mechanobiology studies. Spine (Phila Pa 1976). 2006; 31: 515-22.

46. Chiba K, Andersson GB, Masuda K, Momohara S, Williams JM, Thonar EJ. A new culture system to study the metabolism of the intervertebral disc in vitro. Spine. 1998; 23: 1821-7; discussion 8.

47. Takada T, Nishida K, Doita M, Kurosaka M. Fas ligand exists on intervertebral disc cells: a potential molecular mechanism for immune privilege of the disc. Spine (Phila Pa 1976). 2002; 27: 1526-30.

48. Griffith TS, Brunner T, Fletcher SM, Green DR, Ferguson TA. Fas ligand-induced apoptosis as a mechanism of immune privilege. Science. 1995; 270: 1189-92. doi:10.1126/science.270.5239.1189.

49. Wang J, Tang T, Yang H, Yao X, Chen L, Liu W, et al. The expression of Fas ligand on normal and stabbed-disc cells in a rabbit model of intervertebral disc degeneration: a possible pathogenesis. J Neurosurg Spine. 2007; 6: 425-30. doi:doi:10.3171/spi.2007.6.5.425.

50. Kaneyama S, Nishida K, Takada T, Suzuki T, Shimomura T, Maeno K, et al. Fas ligand expression on human nucleus pulposus cells decreases with disc degeneration processes. J Orthop Sci. 2008; 13: 130-5.

51. Michlewska S, McColl A, Rossi AG, Megson IL, Dransfield I. Clearance of dying cells and autoimmunity. Autoimmunity. 2007; 40: 267-73. 